\title{
Customization of laboratory for radiant cooling ceiling measurements
}

\author{
Stanislav Sehnalek ${ }^{1, *}$ Martin Kolacek ${ }^{1}$ \\ ${ }^{1}$ Department of Automation and Control Engineering, Faculty of Applied Informatics, TBU in Zlin, Nad Stranemi 4511, Zlin, Czech \\ Republic
}

\begin{abstract}
In this article is examine Laboratory of Environmental Engineering at Faculty of applied informatics under Tomas Bata University in Zlin. This laboratory is performing standardized test of special HVAC equipments. This article describes newly made customization for measuring radiant cooling ceilings. Firstly is described previous situation which is concluded by necessary changes. It is mentioned energy supplies and newly made connection for cooling ceilings. Whole article is sum up by description of samples on which would be done verification of measurement space and methodology.
\end{abstract}

\section{Introduction}

Much popularity attains radiant cooling systems thanks to lesser energy consumption, silent operation, significant thermal comfort and convective heat transfer. One of most important representative of this category is the ceiling radiant cooling panels. Those panels can gain high energy efficiency thanks to reduced distribution losses and the fact that uses low-temperature water. $[1,2]$

Because they are able to provide comfortable indoor environment. With these systems is heat exchange done by radiant and convective heat transfer. More than $50 \%$ of heat exchange is covert by radiant heat transfer in conditioned space [3, 4]. This radiation exchange between the radiant surface and occupants allowing air temperature to be at lower level than within conventional systems. This also helps to reduce heat losses from the building which could be significant in mild climates [5]. Furthermore, room air temperature can be maintained at lower values than with conventional all-air systems. With radiant cooling systems is the heat removed from occupants by radiant heat transfer which allowing to maintain the room air temperature to be at comparably higher values. [6]

In Europe are ceiling radiant cooling panels popular. They are selected in initial design phase in accordance to manufactures data. Nevertheless, usually are actual cooling capacity of panels greater than those measured in laboratory. This is caused mainly because of non-standard indoor environment conditions there. This include air velocity, covered area rate, warm outside surfaces and false ceiling area rate. Overview of standardized testing methods for the evaluation for cooling performance are given by Kochendörfer [7]. Design of cooling panels system cold by established by method with the cooling capacity measured governed under laboratory conditions. Actual cooling performance for top insulated and suspended metal ceiling radiant cooling panels and mixes convection

*Corresponding author: sehnalek@utb.cz conditions was provided by Jeong and Mumma [8-10]. Cooling capacity can be enlarge typically by $5 \%$ to $35 \%$ in mechanical ventilated spaces. [11]

He et al. [12] investigated application of radiant cooling ceilings with desk fan. This study shows proper solution for high humid climates combined with extreme temperatures peaks. This solution can partly reduce condensation which would occurs when is temperature of supply water under dew point temperature. In article by Tang et al. [13] is provided study of the mass of condensation water and the departure duration of droplets. The theory is compared with experimental measurement, where result shows that duration decrease where temperature of dew point increase.

In this article will be examine Laboratory of environmental engineering at Faculty of applied informatics under Tomas Bata University in Zlin. This laboratory is performing standardized test of special HVAC equipments such are heat pumps, air condition units, fans, acoustic silencers, valves and others. This article describes newly made customization for measuring radiant cooling ceilings. Firstly is described previous situation which is concluded by necessary changes. It is mentioned energy supplies and newly made connection for cooling ceilings. Whole article is sum up by description of samples on which would be done verification of measurement space and methodology

\section{Methods}

For purpose of measurement was important to modification of laboratory to fulfil measurement procedure and standard CSN EN 14240 [14]. Based on fact that measuring space have to have emissivity better than 0.9 was important to cover recondition unit in indoor part of compensated calorimetric chamber. For this purposes was built separation wall, which divided indoor space into two separated parts. Result of this separation can be seen on figure 2. For projection purposes was used ANSYS SpaceClaim 


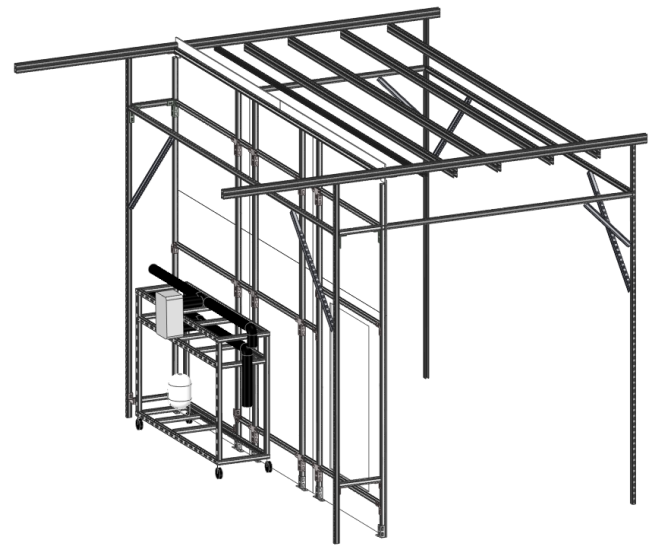

Fig. 1. Frame model.

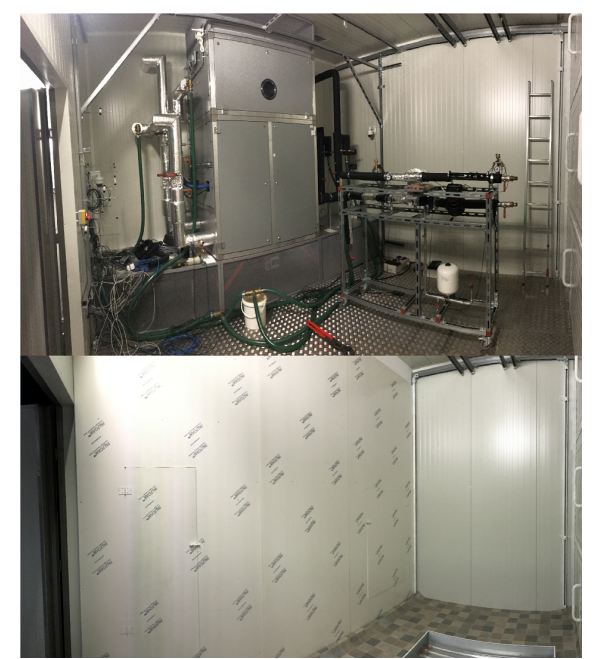

Fig. 2. Indoor space before and after installation of separation wall.

modeling software. Firstly was needed to model current situation and then was made modifications to ensure above mentioned conditions. Previous construction from HILTI channel system was used to hold split units of air conditions units and heat pumps. To this construction was attached new separation wall also made from HILTI channel system and plastic board. Scheme of previous construction with new wall is shown in figure 1. This space is surrounded by compensation spaces which are indoor space, compensation indoor space and compensation outdoor space, see figure 3 .

An integral part of establishing specialized space for measurements of cooling ceilings was also to create a measurement procedure or methodology to measure the cooling performance of this device. This methodology is based on CSN EN 14240 [14].

Calorimetric chamber is capable to ensure air temperatures from $-30{ }^{\circ} \mathrm{C}$ to $40{ }^{\circ} \mathrm{C}$ in outdoor space and compensation outdoor space with whole range of humidity. In indoor space and compensation is indoor space capable to maintain at air temperatures from $5{ }^{\circ} \mathrm{C}$ to $40^{\circ} \mathrm{C}$ and whole range of humidity. The laboratory is equipped with tech-
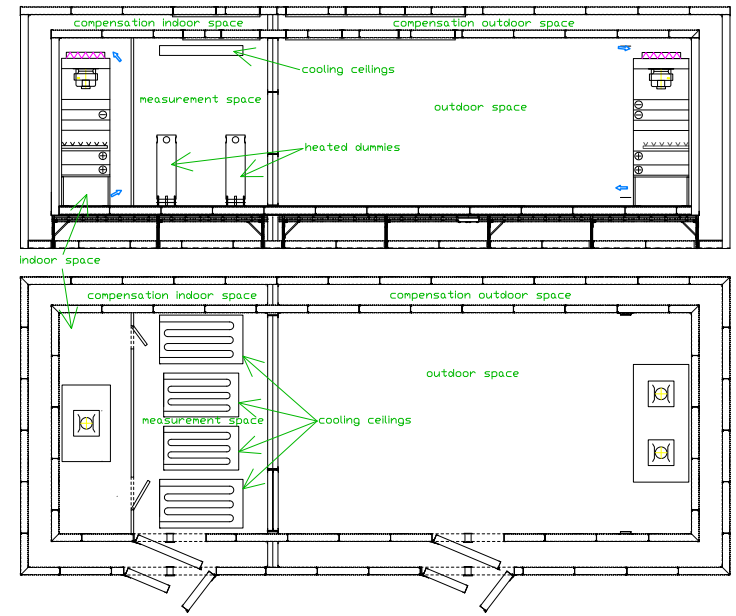

Fig. 3. Scheme of measurement set-up.

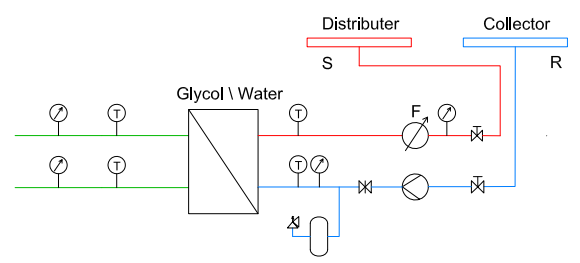

Fig. 4. Scheme of hydraulic exchanger.

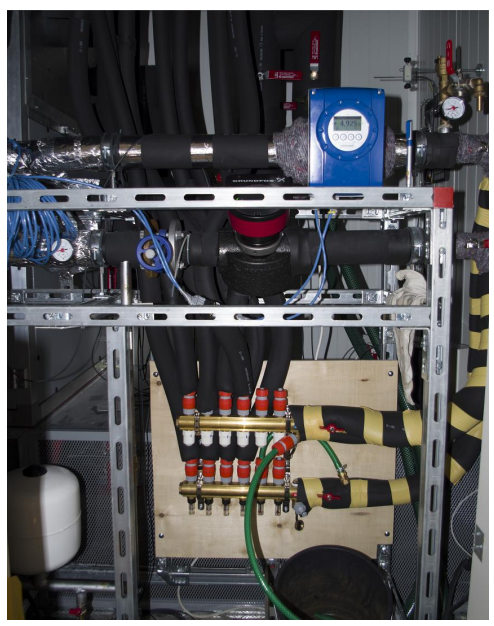

Fig. 5. Actual hydraulic connection.

nology that produce heat/cold to the two tanks of 10001 to ensure this and is based on $40 \%$ glycol. Heat exchanger glycol-water is used for connection of cooling ceilings. Scheme of this unit is depicted on figure 4 and real connection is on figure 5 .

During the test, the surrounding walls must ensure minimal heat losses. Therefore, the air temperature in the surrounding compensating space have to be kept as same as in the measurement space.

The heat load is secured inside the laboratory using electrically heated dummies. Scheme of this dummy is depicted on figure 6 where numbers means: 1 Cover; 24 holes evenly distributed over the perimeter; 33 lamps 60 


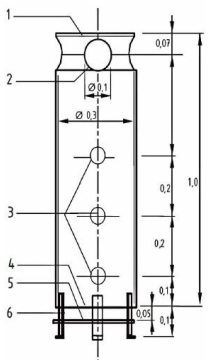

Fig. 6. Scheme of heat dummy [14].

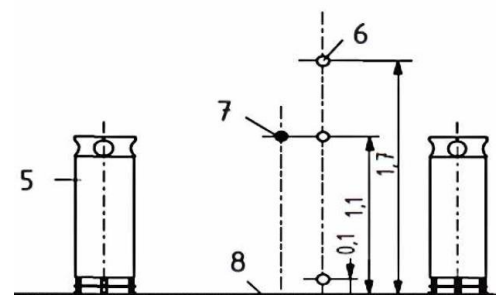

Fig. 7. Positions of measuring instruments [14].

W output per lamp; 4 Without bottom; 5 Bottom; 63 feet distributed around the perimeter. The electric power of these dummies is adjustable by light bulb with a maximum of $180 \mathrm{~W}$. The maximum internal room heat load is $200 \mathrm{~W} \mathrm{~m}^{-2}$. The placement of these dummies was therefore chosen so that the required thermal load values were maintained in accordance to standard requirements.

During the tests, the temperature and humidity of the air, the surface temperatures of the surrounding areas, including the cooling elements, the temperature of the heat transfer medium (water) inside the cooling elements are measured. The measuring room also measures the temperature of the spherical thermometer together with the exact positions of the temperature sensors as shown in the following figure 7 where numbers means: 5 heat dummy; 6 thermometers; 7 globe thermometer.

To determine the cooling capacity of the device, it is also necessary to measure the volume flow of water flowing into the cooling ceilings. The standard furthermore provides for a residence time of at least 60 minutes during which cooling performance is measured.

In this article is only considered modification of the laboratory and requirements to perform measurements of cooling radiant ceilings.

\subsection{Cooling ceilings}

For validation purposes were made radiant cooling ceilings. To verify methodology and customization in laboratory was designed two sizes of cooling ceiling. First size is $1.6 \mathrm{~m}$ wide and second one is $1.4 \mathrm{~m}$ wide, other dimensions are same. The cooling ceilings are made from $1 \mathrm{~mm}$ thick metal plate with white finish and high emissivity. Whole cooling ceiling consists of above mentioned metal tank in which is placed cooper spiral exchanger. The ceiling is shown on figure 8 .

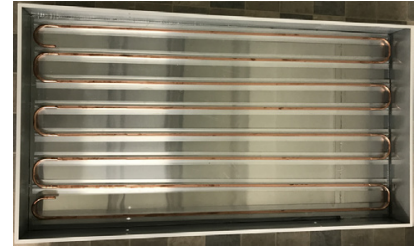

Fig. 8. Real model of radiant cooling ceiling.

\section{Conclusion}

In this article was examined Laboratory of environmental engineering at Faculty of applied informatics under Tomas Bata University in Zlin. This laboratory is performing standardized tests of special HVAC equipments such are heat pumps, air condition units, fans, acoustic silencers, valves and others. This article described newly made customization for measuring radiant cooling ceilings. Firstly was described previous situation, which was concluded by necessary changes. It was mentioned energy supplies and newly made connection for cooling ceilings. Whole article sum up by description of samples on which would be done verification of measurement space and methodology.

Newly made modification of laboratory empower research team to make research in radiant ceiling systems as well as application of new materials for this purposes. It also allow to perform certified measurements for companies which are operate in this field.

Modification used by research team is in accordance with standards and legislation. Contribution can be seen in application of standard conditions and developing modification to already established laboratory. The full validation of modification and measurement on cooling ceiling samples will be describe in further article. Will be also done comparison of cooling ceiling with application of special phase change material (PCMs) and without of PCMs.

This work was supported by the Ministry of Education, Youth and Sports of the Czech Republic within the National Sustainability Programme project No. LO1303 (MSMT-7778/2014) and also by the Internal Grant Agency of Tomas Bata University in Zlin under the project No. IGA/CebiaTech/2018/001.

\section{References}

[1] G. Yu, L. Xiong, C. Du, H. Chen, Case Studies in Thermal Engineering 11, 35 (2018)

[2] B. Olesen, ASHRAE Journal 44, 19 (2002), cited By 129

[3] Ashrae, Ashrae Handbook 2016: Hvac Systems and Equipment, ASHRAE handbook (ASHRAE, Atlanta, 2016)

[4] R. Karadağ, Energy Conversion and Management 50, 1 (2009)

[5] H. Salt, Building and Environment 20, 10 (1985)

[6] K.N. Rhee, K.W. Kim, Building and Environment 91, 24 (2015) 
[7] C. Kochendoerfer, Transactions - American Society Of Heating Refrigerating And Air Conditioning Engineers 102, 7 (1996)

[8] J.W. Jeong, S.A. Mumma, Applied Thermal Engineering 23, 13 (2003)

[9] J.W. Jeong, S.A. Mumma, Applied Thermal Engineering 24, 17 (2004)

[10] J.W. Jeong, S.A. Mumma, Building and Environment 42, 9 (2007)
[11] Z. Tian, X. Yin, Y. Ding, C. Zhang, Energy and Buildings 47, 6 (2012)

[12] Y. He, X. Wang, N. Li, M. He, D. He, K. Wang, Building and Environment 122, 23 (2017)

[13] H. Tang, T. Zhang, X. Liu, Y. Jiang, Building and Environment 114, 445 (2017)

[14] CSN EN 14240 - Ventilation for buildings - Chilled ceilings - Testing and rating, Standard, Czech office for standards metrology and testing, Prague (2004) 